\title{
WETLANDS AS AN ALTERNATIVE STABLE STATE IN DESERT STREAMS
}

\author{
JAMES B. HEFFERNAN ${ }^{1}$ \\ School of Life Sciences, Arizona State University, Tempe, Arizona 85287-4601 USA
}

\begin{abstract}
Historically, desert drainages of the American southwest supported productive riverine wetlands (ciénegas). Region-wide erosion of ciénegas during the late 19th and early 20th century dramatically reduced the abundance of these ecosystems, but recent reestablishment of wetlands in Sycamore Creek, Arizona, USA, provides an opportunity to evaluate the mechanisms underlying wetland development. A simple model demonstrates that density-dependent stabilization of channel substrate by vegetation results in the existence of alternative stable states in desert streams. A two-year (October 2004-September 2006) field survey of herbaceous cover and biomass at 26 sites located along Sycamore Creek is used to test the underlying assumption of this model that vegetation cover loss during floods is density dependent, as well as the prediction that the distribution of vegetation abundance should shift toward bimodality in response to floods. Observations of nonlinear, negative relationships between herbaceous biomass prior to flood events and the proportion of persistent vegetation cover were consistent with the alternative stable state model. In further support of the alternative-state hypothesis, vegetation cover diverged from an approximately normal distribution toward a distinctly bimodal distribution during the monsoon flood season of 2006. These results represent the first empirically supported example of alternative-state behavior in stream ecosystems. Identification of alternative stable states in desert streams supports recent hypotheses concerning the importance of strong abiotic-disturbance regimes and biogeomorphic mechanisms in multiple-state ecosystems.
\end{abstract}

Key words: alternative stable states; biogeomorphology; ciénega; disturbance; floods; habitat restoration; regime shift; Sycamore Creek, Arizona, USA; wetland.

\section{INTRODUCTION}

Alternative stable states in ecological systems occur when self-reinforcing feedbacks generate multiple stable equilibria under a given set of conditions (Holling 1973, May 1977). Such systems are subject to catastrophic reorganization (or regime shift) either in response to changing conditions or severe perturbation (Scheffer et al. 2001). Alternative-state dynamics are perhaps best understood in lakes (e.g., Carpenter 2003), but have been documented in a variety of ecological systems (reviewed by Didham et al. [2005]). Of particular concern for restoration and management is that multiple-state systems often exhibit hysteretic behavior, where reestablishment of pre-shift conditions fails to restore the original system state (Suding et al. 2004).

In light of the difficulty of recognizing and delineating stable-state thresholds and of the costs associated with reversing state transitions, determining general circumstances that promote the occurrence of multiple states represents a pressing need in ecological theory (Scheffer and Carpenter 2003, Schroder et al. 2005, Groffman et al. 2006). In many cases, alternative states are characterized by distinct sets of morphologic and life-history

Manuscript received 8 June 2007; revised 18 September 2007; accepted 25 September 2007. Corresponding Editor: C. R. Hupp.

${ }^{1}$ Present address: School of Forest Resources and Conservation, University of Florida, Gainesville, Florida 326110410 USA. E-mail: j.heffernan@ufl.edu traits of primary producers which are reinforced by positive feedbacks with the physical environment (Scheffer et al. 2001). Didham et al. (2005) recently posited that systems with severe abiotic-disturbance regimes are more likely to exhibit alternative states. Dent et al. (2002) suggest that alternative states arise via biotic interactions in infrequently disturbed systems such as lakes, and via abiotic mechanisms in disturbance-driven systems such as streams. The extreme disturbance regime of streams in the southwestern United States (Poff and Ward 1989) provides an excellent test case for these hypotheses.

Desert streams are subject to frequent and severe hydrologic disturbance in the form of both flash floods and drying (Fisher et al. 1982, Stanley et al. 1997). In the absence of herbaceous vegetation, coarse channel sediments and associated biota are easily mobilized by frequent flash floods (Grimm and Fisher 1989). Ecological and biogeochemical processes are driven by postflood algal succession (Fisher et al. 1982, Grimm 1987), which in turn is influenced by hydrologic and nutrient exchange between the surface stream and hyporheic and riparian zones (Fisher et al. 1998).

Historically, riverine wetlands (ciénegas), characterized by wide, slow-moving flow through extensive emergent vegetation, were a common feature of the arid drainages of Arizona (Hendrickson and Minckley 1984). Region-wide erosion during the late 19th and early 20 th century dramatically reduced the abundance of these ecosystems, since the formation of deeply incised 


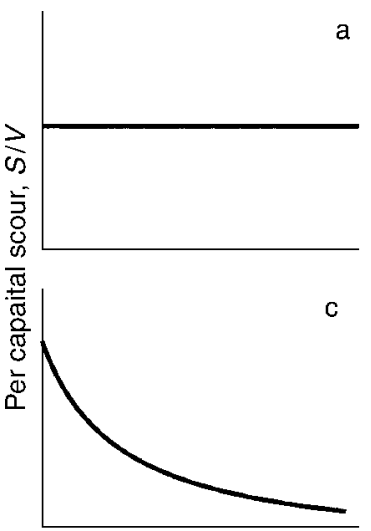

Vegetation abundance, $V$

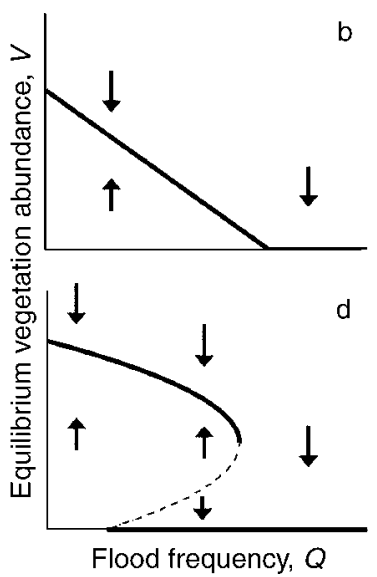

FIG. 1. Effects of density-dependent flood response on vegetation dynamics. Per capita scour is the proportional loss of vegetation due to flood scour $(S)$ relative to vegetation abundance $(V)$, a dimensionless density ranging from 0 to 1 . In the case where (a) vegetation losses during floods ( $S$, mortality due to scour) are independent of vegetation abundance $(V)$, (b) equilibrium vegetation abundance decreases with increasing discharge (flood frequency, $Q$ ) until the stable equilibrium is at zero vegetation. If (c) vegetation losses are negatively density dependent, then (d) multiple equilibria exist at intermediate discharge. In terms of model behavior, changes in flood magnitude $\left(r_{\mathrm{S}}\right)$ have the same effect as changes in flood frequency. Solid lines indicate stable equilibria, and dashed lines indicate unstable equilibria. Arrows indicate direction of vegetation change.

channels (arroyos) through wetland sediments resulted in water-table declines and further loss of wetland vegetation. Loss of ciénegas is generally attributed to increases in cattle density, climate variation, or some interaction between the two (reviewed by Graf [1988]). Over longer time scales, sediment and pollen records from floodplain sediments suggest that these wetlands underwent several cycles of erosion and rebuilding during the Holocene (Martin 1963). Several researchers have hypothesized positive feedbacks between vegetation and channel stability that would promote the existence of alternate states in desert streams (Hendrickson and Minckley 1984, Dent et al. 2002).

Recent increases in herbaceous vegetation at Sycamore Creek, Arizona, USA, a site of long-term ecosystem research, provide an opportunity to examine the mechanisms of wetland formation in desert streams. Since 2001, when the U.S. Forest Service eliminated grazing from the Sunflower allotment of the Tonto National Forest as a response to ongoing drought, the abundance of herbaceous vegetation in the active channel of Sycamore Creek has increased dramatically in some locations (Heffernan 2007; see Appendix A). At sufficient density, plant establishment initiates a suite of changes in the physical, chemical, and biological structure of desert streams, including reduction of surface-flow velocity, deposition of fine sediments, hyporheic anoxia, and increased standing crops of live biomass and organic detritus. Prior to 2000, macrophyte patches were present but rare and limited in spatial extent (i.e., patches less than $10 \mathrm{~m}^{2}$ in area; Dudley and Grimm 1994). As of 2005, development of wetlands had occurred over $\sim 20 \%$ of the main stem of Sycamore Creek (Heffernan 2007).

The primary objective of this study is to evaluate the hypothesis that ciénegas constitute an alternative stable state in desert streams. A simple model shows that positive density dependence of vegetation resistance to flood disturbance can generate alternative stable states if stabilization by vegetation is large relative to the inherent physical stability of sediments. Data from a two-year field survey are used to evaluate two predictions of the model. If the alternative-state model is correct, aboveground biomass will be negatively correlated with vegetation removal. This prediction is necessary, but not sufficient, support for the alternative-state hypothesis, as the same pattern could result from variation among sites in inherent (i.e., abiotic) flood resistance based on local geomorphic structure (e.g., variation in particle size and arrangement). However, the alternative stable-state hypothesis also leads to the prediction that the distribution of vegetation abundance among sites will diverge toward a bimodal distribution in response to flood events. This prediction discriminates between the multiple-state and abiotic hypotheses as the latter provides no rationale for such a change in distribution shape.

\section{Model structure and analysis}

The dynamics of vegetation were modeled using the logistic growth equation to describe vegetation growth and a form of the Michaelis-Menten equation to describe vegetation mortality due to flood scour:

$$
\frac{d V}{d t}=G-S=V(1-V)-V\left(\frac{r_{\mathrm{S}} \times Q}{K_{\mathrm{S}}+c_{\mathrm{S}} \times V}\right)
$$

where $G$ is production (i.e., growth), $S$ is mortality due to flood scour, $V$ is dimensionless vegetation density (ranging from 0 to 1 ), $Q$ is flood frequency, $r_{\mathrm{S}}$ is a coefficient relating scour mortality to flood frequency (and thus integrates flood magnitude and channel slope), $K_{\mathrm{S}}$ is a measure of the stability of channel sediments (in the absence of vegetation), and $c_{\mathrm{S}}$ is the per capita stabilization of sediments by vegetation. Time $(t)$ is scaled to vegetation growth rate. Model structure was chosen based on the simplest analytical forms that described exponential growth to some carrying capacity and asymptotically declining per capita mortality.

The potential for alternative-state behavior in this model depends on the relative strength of abiotic and biotic resistance to erosion (see Appendix B). If the density-dependent flood response is absent or weak $\left(c_{\mathrm{S}}\right.$ $<K_{\mathrm{S}}$; Fig. 1a), equilibrium vegetation exhibits a single positive equilibrium below a threshold in flood frequency $\left(Q<K_{\mathrm{S}} / r_{\mathrm{S}}\right)$, above which the equilibrium biomass is zero (Fig. 1b). However, when the stabilizing effect of vegetation is large $\left(c_{\mathrm{S}}>K_{\mathrm{S}}\right.$; Fig. 1c), vegetation biomass 
exhibits two stable equilibria (Fig. 1d) across a range of flood regimes defined by

$$
\frac{K_{\mathrm{S}}}{r_{\mathrm{S}}}<Q<\frac{\left(c_{\mathrm{S}}+K_{\mathrm{S}}\right)^{2}}{4 r_{\mathrm{S}} c_{\mathrm{S}}} .
$$

Under flood regimes within this range, desert streams will tend to occupy one of two states: a gravelbed state in which low vegetation abundance is maintained by high mortality during flood events, and a ciénega state in which high vegetation abundance persists due to low flood-induced mortality. This behavior can occur only when vegetation exerts a significant stabilizing influence on channel sediments, and the specific range of flood regimes that can be withstood will depend on the resistance to scour of both abiotic and biotic channel elements.

\section{Methods \\ Study site}

Sycamore Creek, Arizona, USA, a spatially and temporally intermittent stream in the Tonto National Forest near Phoenix, Arizona, drains a mountainous, $505-\mathrm{km}^{2}$ catchment of volcanic and metamorphic rocks, poorly developed soils, and Sonoran desert scrub vegetation (Carnegiea-Cercidium). Geomorphic structure in Sycamore Creek changes with elevation, with steep upper canyon reaches separated from the broad, flat, sand phase by a transition region where unconstrained valleys $(>200 \mathrm{~m}$ wide) alternate with constrained sections $<60 \mathrm{~m}$ wide. Precipitation is bimodally distributed, with $30 \%$ of precipitation occurring in intense, brief, and spatially isolated summer monsoon storms, and $70 \%$ associated with winter frontal storms of lower intensity, but greater duration and extent (Welter et al. 2005). Low infiltration capacity and high rain intensity result in an extremely flashy hydrograph. Baseflow, supplied by upstream alluvial aquifers, is sustained for much of the year in constrained sections (Stanley et al. 1997).

Surface-water permanence and flood frequency, timing, and magnitude differed considerably between years of the study (October 2004-September 2006; Fig. 2a). In the winter of 2005, several large floods, including one with a peak discharge of $310 \mathrm{~m}^{3} / \mathrm{s}(11000$ cubic feet per second, cfs), resulted in sustained baseflow throughout the main stem of Sycamore Creek for the remainder of the year. A weak summer monsoon and the absence of any significant rainfall during the winter of 2006 resulted in significant drying during the spring and summer of 2006. However, the subsequent monsoon season yielded several significant floods of up to $110 \mathrm{~m}^{3} / \mathrm{s}$ (3700 cfs).

\section{Vegetation survey}

In October 2004 I established 18 sites characterized by a range of historic surface water permanence (Appendix C). Sites chosen were riffles and runs (i.e., large pools were excluded) located in relatively straight channel sections free of large debris, tree islands, and other obstructions. At each site, three transects spanning the bank-full active channel (i.e., from bank to bank but not including any elevated riparian terrace) were established at $10-\mathrm{m}$ intervals. Eleven of these sites were located downstream of the confluence of Sycamore Creek and Mesquite Wash, a major tributary $\left(\sim 100-\mathrm{km}^{2}\right.$ catchment area) that can produce significant flooding in Sycamore Creek. In March 2005, following an extremely wet winter, eight additional sites, three of which were below Mesquite Wash, were established to increase the range of stream permanence among sites.

Sites were sampled approximately every three weeks from October 2004 to September 2006. At 12 evenly spaced points along each transect, plant taxon, height, and condition (live or dead), as well as surface-water depth (if present) were recorded. Taxon-specific relationships between mean plant height and aboveground ash-free dry mass (AFDM) were used to estimate biomass from plant height measurements at each point (Appendix B). In the case of rare species for which specific height-biomass relationships were not available, a generic equation generated using all data was applied. Since such points comprised only $5 \%$ of all survey points, any error associated with this is unlikely to be consequential for site-scale estimates of aboveground biomass. Following the sequence of large floods that occurred in the winter of 2005, locations where aboveground biomass was absent but where root mats had persisted at the benthic surface were also recorded. Senesced plants and root mats were assigned a biomass value of 0 , but were counted as vegetated cover. Standing biomass for each site was then calculated as the average of point biomass estimates for that site.

\section{Data analysis}

For each survey year, the duration of surface water was calculated as the proportion of sampling dates during the growing-season year in which surface water occurred at one or more sampling points within that site. Regression analysis was used to relate duration of surface flow to peak aboveground biomass during that year. For 2005, absolute cover remaining after the large floods of that year was included as an additional predictor variable. Since no floods of even moderate size occurred during the winter and spring of 2006, cover following the monsoon flood season of 2005 was used in analysis of 2006 peak biomass.

To evaluate the importance of flood size on vegetation persistence, I calculated total cover loss as the difference in the sum of vegetation cover from all sites prior to and following each flood event. Regression analysis was used to determine the relationship between flood size (logtransformed peak discharge) and total cover loss across all sites. In cases where several floods occurred between survey dates, the peak discharge of the largest flood was used in this analysis. Data from an earlier survey effort 


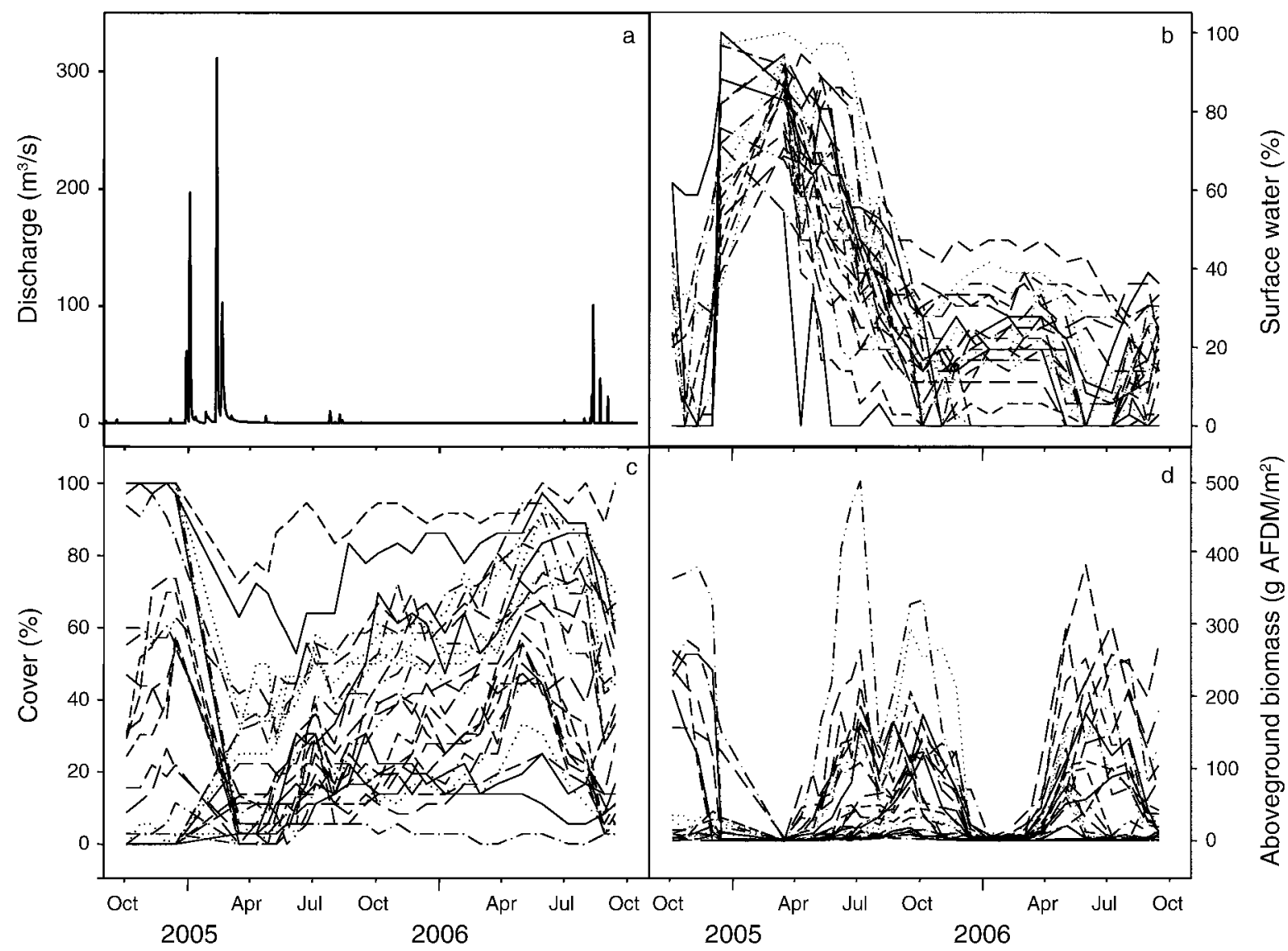

FIG. 2. Discharge regime (a) during the study period and time series of (b) surface-water cover, (c) vegetation cover, and (d) herbaceous biomass at 26 sites along Sycamore Creek, Arizona, USA, from October 2004 to September 2006. The relative magnitude of winter and summer rains varied considerably between years, with large winter floods and a weak monsoon during 2005, and an unusual absence of any winter floods and a strong monsoon season during 2006. Discharge data are from USGS stream gauge on Sycamore Creek (number 09510200). Biomass is measured on an ash-free dry mass (AFDM) basis. Each line in panels (b)-(d) represents data from a single study site.

that used fewer ( $n=6$ sites), larger (200-m) sites (Heffernan 2007) was also included in this analysis.

In order to test the assumption of the model that per capita flood mortality decreases with increasing biomass, per capita mortality $(S / V)$ at each site for each flood was calculated as

$$
\frac{S}{V}=\frac{C_{0}-C_{1}}{C_{0}}
$$

where $C_{0}$ is the percent cover of herbaceous plants (summing live, senesced, and root mat cover) in the sampling date immediately preceding the flood, $C_{1}$ is the percent cover in the sampling date immediately following the flood event, $S$ is vegetation mortality due to flood scour, and $V$ is dimensionless vegetation density (range: $0-1)$. Changes in cover were used as the metric of flood survival because biomass estimates, based on plant heights in their undisturbed growth form, were least reliable immediately following floods.

For each flood, regression analysis was used to test the hypothesis that vegetation persistence is density depen- dent. Based on the relationship between biomass and flood mortality in the alternative stable-state model, biomass was related to proportional cover loss using an analagous nonlinear regression equation of the form

$$
y=\frac{a}{1+b x}
$$

where $y$ is proportional cover loss (Eq. 3), $x$ is aboveground biomass at a given site, and $a$ and $b$ are regression parameters describing the ratio of erosive forces to abiotic resistance $\left(r_{\mathrm{S}} \times Q / K_{\mathrm{S}}\right)$ and of biotic to abiotic resistance $\left(c_{\mathrm{S}} / K_{\mathrm{S}}\right)$, respectively. This analysis was performed for all flood events in which total cover loss was $>5 \%$. In two instances (29 July 2005 and 12 August 2006), only data from the 14 sites located below Mesquite Wash, whose watershed was the origin of those floods, were included in the analysis. Prior to the floods of early 2005, nearly all aboveground biomass was senesced and consequently aboveground biomass estimates at most sites were zero immediately prior to the floods. Because senesced structures and roots of 
perennial species may still stabilize channel sediments, peak biomass present during the preceding two months was used as the predictor variable in the regression analysis for this flood event. This analysis was also performed for the monsoon season of 2004, for which data on six sites were available from an earlier survey effort.

The distribution of vegetation cover among the 26 sites before and after floods was evaluated to assess the prediction that vegetation abundance should diverge into a bimodal distribution. The normality of site cover prior to and following each flood event was assessed using Lilliefors' test. As described by Van de Koppel et al. (2001), vegetation cover frequency was fit to a bimodal distribution given by the mixture of two normal distributions:

$$
P=q \times \mathcal{N}\left(\mu_{1}, \sigma_{1}\right)+(1-q) \times \mathcal{N}\left(\mu_{2}, \sigma_{2}\right)
$$

where $q$ (a constant between 0 and 1) represents the contribution of the two normal distributions, and $\mathcal{N}$ is a normal distribution with mean $\mu_{i}$ and standard deviation $\sigma_{i}$. Determination of best model fit between the unimodal and bimodal distributions was based on Bayes' information criterion (BIC), with higher values indicating superior fit to the data. This analysis was carried out using the MCLUST package on R (Fraley and Raftery 1999). All other statistical analyses were carried out using SYSTAT version 10.0 statistical software (SPSS 2000).

\section{RESULTS}

Surface-water permanence varied between years and among sites. Surface water was present through the entire growing season (March-October) of 2005 at all sites but one owing to the large floods early in that year, but disappeared from many sites during the summer of 2006 due to the extremely dry winter of 2006 (Fig. 2b). Surface-water permanence ranged from $0 \%$ to $100 \%$ of the growing season in $2006(70.2 \% \pm 6.5 \%$ [mean \pm $\mathrm{SE]}$ ). Surface-water presence increased temporarily in response to the monsoon season during both years.

Patterns in vegetation cover were driven by losses associated with the large floods of the 2005 winter (Fig. 2c), which removed all aboveground biomass from the active channel at all sites and significantly reworked channel features at many sites. In locations where significant vegetation cover persisted, that cover consisted entirely of dense root mats that resprouted aboveground structures within days of flood-peak abatement. Vegetation cover increased steadily during the growing season of 2005, held constant through the dry winter of 2006, and increased again during the spring and early summer of 2006. Monsoon floods between late June and mid-August reduced vegetation cover at most sites.

Aboveground biomass exhibited a marked seasonal pattern, with the majority of production occurring between March and October, and peaking in June and
July (Fig. 2d). Vegetation senesced in early December in both 2004 and 2005. Vegetation growth began again in March and April, and aboveground biomass peaked during early summer. Across all sites, peak aboveground biomass ranged from 8 to $496 \mathrm{~g} A F D M / \mathrm{m}^{2}$ in 2005 and from 6 to $380 \mathrm{~g} \mathrm{AFDM} / \mathrm{m}^{2}$ in 2006 (mean $\pm \mathrm{SE}=116 \pm$ $23 \mathrm{~g} / \mathrm{m}^{2}$ in $2005 ; 136 \pm 20 \mathrm{~g} / \mathrm{m}^{2}$ in 2006). In densely vegetated locations, observed August declines in aboveground biomass are likely methodological artifacts related to the flattening of vegetation by floods, rather than actual declines in biomass during that time.

The best predictor of vegetation production differed between the growing seasons of 2005 and 2006. During 2005, surface water was present at all sites but one from January to September, and therefore had little power to explain variation in production. Vegetation cover at the beginning of the growing season (which reflected cover persistence during the preceding winter floods) was an excellent predictor of subsequent peak biomass $\left(r^{2}=\right.$ 0.69, $P<0.001$; Fig. 3a). In contrast, surface-water permanence was a significant predictor of peak aboveground biomass during $2006\left(r^{2}=0.36, P<0.001\right.$; Fig. $3 b)$. Vegetation cover following the preceding flood season did not explain any additional variance in 2006 peak biomass.

Total vegetation cover loss due to flood scour ranged from $0 \%$ to $76 \%$ and was significantly related to peak flood discharge $\left(r^{2}=0.83, P<0.0001\right.$; Fig. 4). Losses were $<20 \%$ for all floods with peak discharge $<20 \mathrm{~m}^{3} / \mathrm{s}$. Within flood events, relationships between herbaceous biomass and per capita cover loss were consistently negative (Fig. 5) and, with the exception of an early pilot study, statistically significant (Table 1).

The response of vegetation-cover distributions varied among flood seasons. In response to the large floods of winter 2005, vegetation cover shifted from a relatively even distribution toward a highly skewed distribution with only a few sites maintaining abundant vegetation cover (Appendix E). At the time of the 2005 monsoon, vegetation cover was still $<60 \%$ at most sites. The small floods that occurred during that monsoon skewed the distribution more heavily toward low vegetation cover, but did not significantly reduce cover in the few more densely vegetated sites (Appendix E). Prior to the 2006 monsoon season, vegetation cover was approximately normally distributed, but shifted toward an increasingly bimodal distribution in response to a series of moderate floods (Fig. 6). Initially, vegetation-cover distribution was best described by a single normal distribution, but was better described by a mixture of two normal distributions on the subsequent three dates during the 2006 monsoon season (Table 2).

\section{Discussion}

The results of this study support the hypothesis that wetland and gravel-bed states constitute alternative stable states in desert streams. Observed negative relationships between aboveground biomass and pro- 

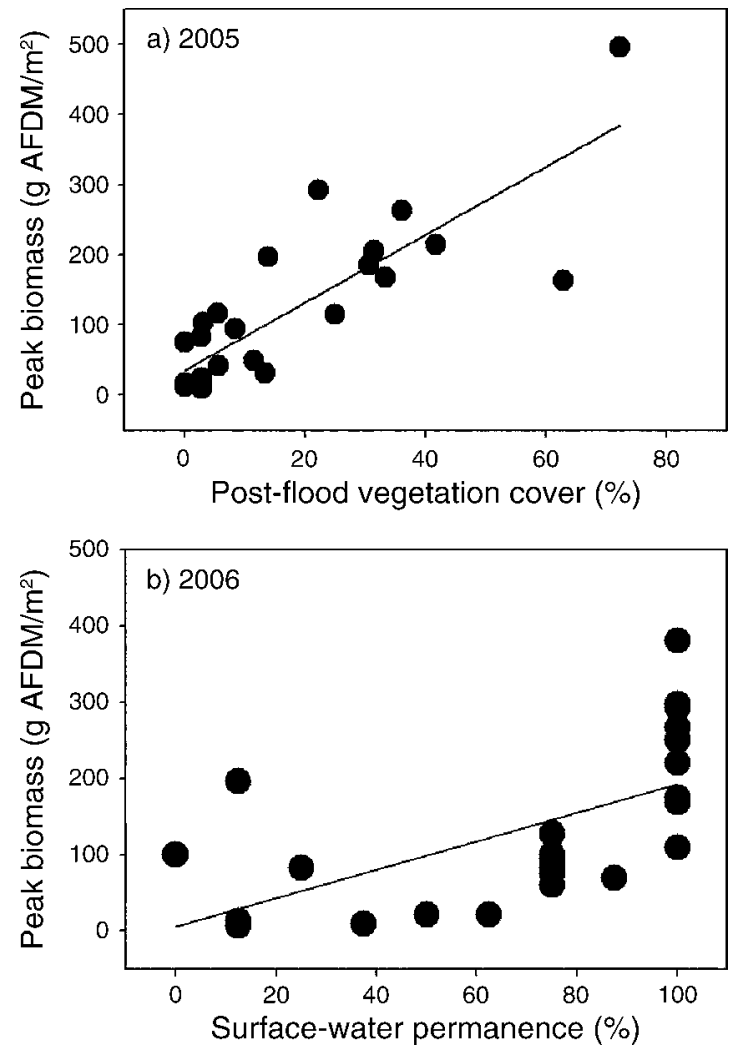

FIG. 3. Effects of flood survival and surface water permanence on herbaceous aboveground production (as measured by peak biomass). (a) During 2005, surface water was present at all sites throughout the growing season (MarchOctober). Peak biomass was significantly related to vegetation persistence during the preceding winter floods. (b) During 2006, no significant winter floods occurred, and peak biomass was best predicted by surface-water permanence. Lines are best-fit least mean-square regression.

portional cover loss during flood events (Fig. 5) are consistent with the stabilizing mechanism that generates multiple states in the vegetation model (Fig. 1). While it is possible that these relationships are the result of variation in abiotic erosion resistance, site selection was intended to minimize such variation. These observations are consistent with studies in a variety of systems demonstrating the stabilizing effect of vegetation on upland, coastal, and fluvial landforms (e.g., Smith 1976, Vaneerdt 1985, Schmidt et al. 2001). The persistence of root mats and associated fine sediments during the powerful floods of January-February 2005 further indicates that dense vegetation is responsible for high sediment stability rather than vice versa. The relationship between vegetation-cover persistence and subsequent productivity (Fig. 3a) closes the positive feedback loop wherein greater production leads to greater flood resistance that further sustains abundant biomass.

Changes in the distribution of vegetation abundance among sites provide additional evidence in support of the alternative stable-state model. Specifically, vegeta- tion abundance diverged into a bimodal distribution in response to floods of the 2006 monsoon (Fig. 6), consistent with the existence of multiple basins of attraction within this system. While the winter and monsoon floods of 2005 did not cause similar divergence (Appendix E), the alternative-state model would not predict that effect in response to large flood events (winter 2005), or when biomass distribution was already skewed toward low vegetation abundance (summer 2005). These observations are inconsistent with abiotic control of erosion resistance, which would be expected to result in a unimodal distribution.

The catastrophic nature of ciénega erosion and arroyo formation in the American southwest (Hendrickson and Minckley 1984) further supports the hypothesis that desert streams exhibit multiple biogeomorphic equilibria. While early investigations of ciénega erosion in this region attributed channel change primarily to increases in grazing pressure, more recent research has emphasized the role of climate variation, with cattle viewed as a local contributing factor (Graf 1988). The model of wetland formation presented here and the data that support it are consistent with that shift in thinking, suggesting that increases in the frequency of floods $(Q)$ or magnitude of floods $\left(r_{\mathrm{S}}\right)$ could trigger a shift from ciénega to gravelbed state. The dramatic effect of flood size on vegetation persistence (Fig. 4) suggests that the recurrence of large floods will be of particular importance, even if their frequency remains relatively constant. Against a background of more typically sized floods, such events would, in effect, represent stochastic declines in vegetation, which could be subsequently maintained by smaller, more frequent floods. Other disturbances, including drought, changes in grazing regime, or changes in resource (e.g., nitrogen) availabil-

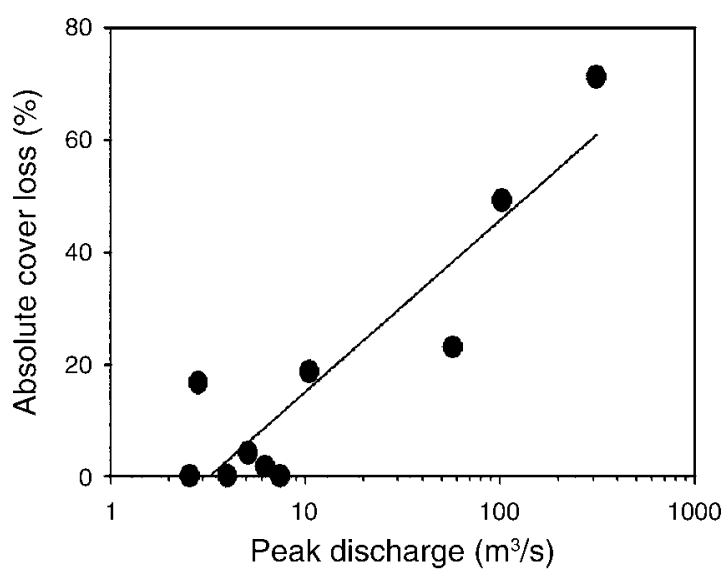

FIG. 4. Relationship between peak-flood size and absolute loss of vegetation cover. Each point represents a single flood event between August 2004 and September 2006. Absolute cover-loss data are the percentage decrease in the sum of vegetation cover from all 26 sites at each flood event. The line represents the best-fit least mean-square regression of $\ln ($ peak discharge) on absolute cover loss, $y=-15.6+13.3 \times \ln (x)$. 

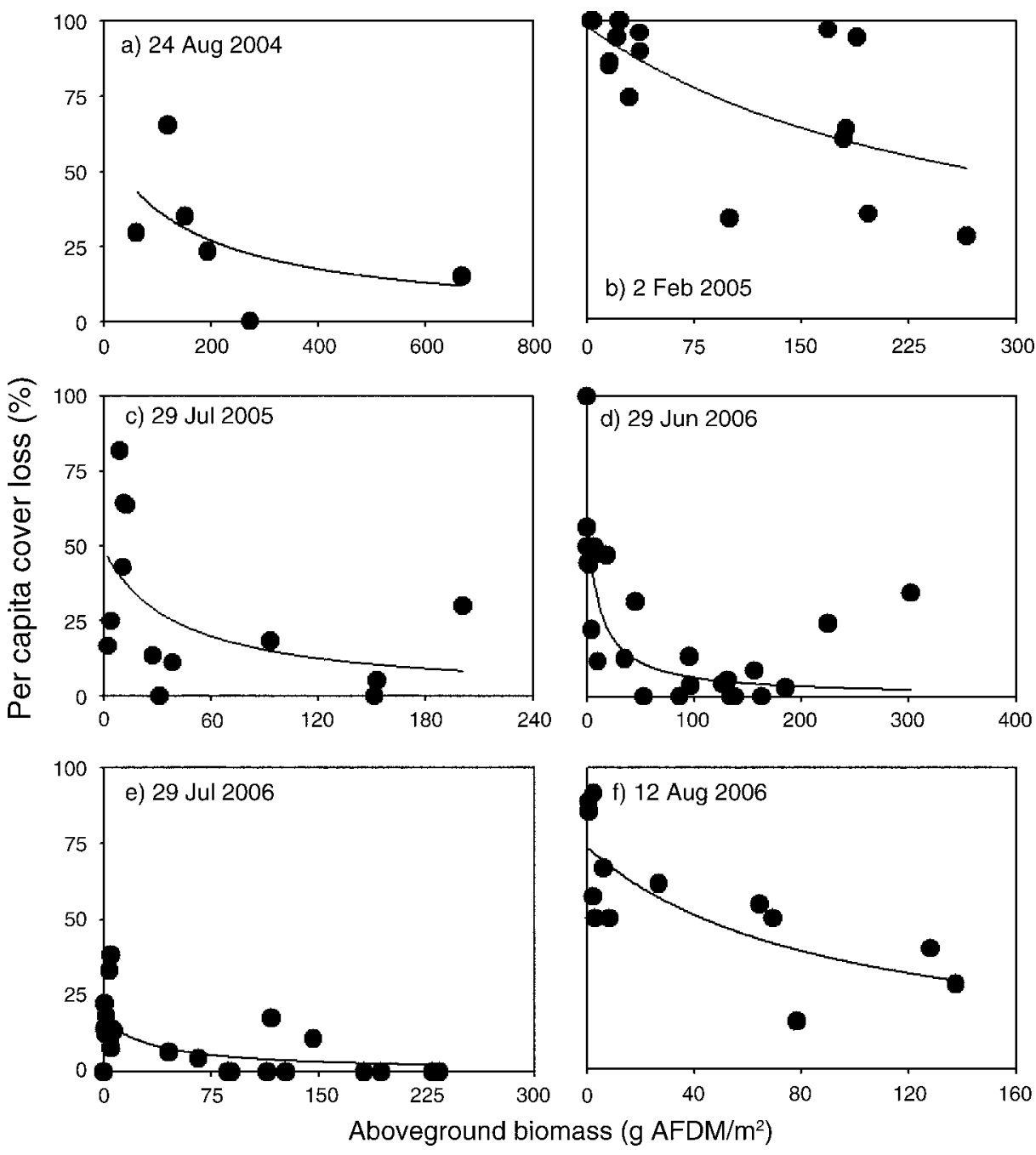

FIG. 5. Relationship between aboveground herbaceous biomass and per capita (proportional, calculated for each site individually) flood losses during six specific floods (a-f). Lines represent best-fit nonlinear regressions based on Eq. 5. Statistical results are presented in Table 1.

TABLE 1. Results of nonlinear (Eq. 4) regression analysis of effect of herbaceous biomass $(x)$ on proportional survival of vegetation cover $(y)$ for six flood events during the study period.

\begin{tabular}{lcccccc}
\hline \hline & & \multicolumn{4}{c}{ Parametersł } \\
\cline { 4 - 5 } \multicolumn{1}{c}{ Date } & Flood size $\left(\mathrm{m}^{3} / \mathrm{s}\right)$ & $n \dagger$ & $a$ & $b$ & $r^{2}$ & $P$ \\
\hline 24 August 2004 & 57 & 6 & 56.5 & 0.0038 & 0.30 & 0.24 \\
2 February 2005 & 310 & 18 & 98.5 & 0.0036 & 0.44 & 0.0035 \\
29 July 2005 & 10.5 & 14 & 49.3 & 0.0025 & 0.27 & 0.069 \\
29 June 2006 & 2.8 & 26 & 60.2 & 0.086 & 0.64 & $<0.001$ \\
29 July 2006 & 5.1 & 26 & 17.7 & 0.030 & 0.39 & 0.001 \\
12 August 2006 & 102 & 14 & 73.8 & 0.011 & 0.57 & 0.003 \\
\hline
\end{tabular}

$\uparrow$ The number of sites used in the regression.

\pm Parameters $a$ and $b$ describe the ratio of erosive forces to abiotic resistance $\left(r_{\mathrm{S}} \times Q / K_{\mathrm{S}}\right)$ and of biotic to abiotic resistance $\left(c_{\mathrm{S}} / K_{\mathrm{S}}\right)$, respectively, where $r_{\mathrm{S}}$ is a coefficient that relates mortality to flood frequency, $Q$ is flood frequency, $K_{\mathrm{S}}$ is a measure of stability of channel sediment in the absence of vegetation, and $c_{\mathrm{S}}$ is per capita stabilization of sediments by vegetation. 


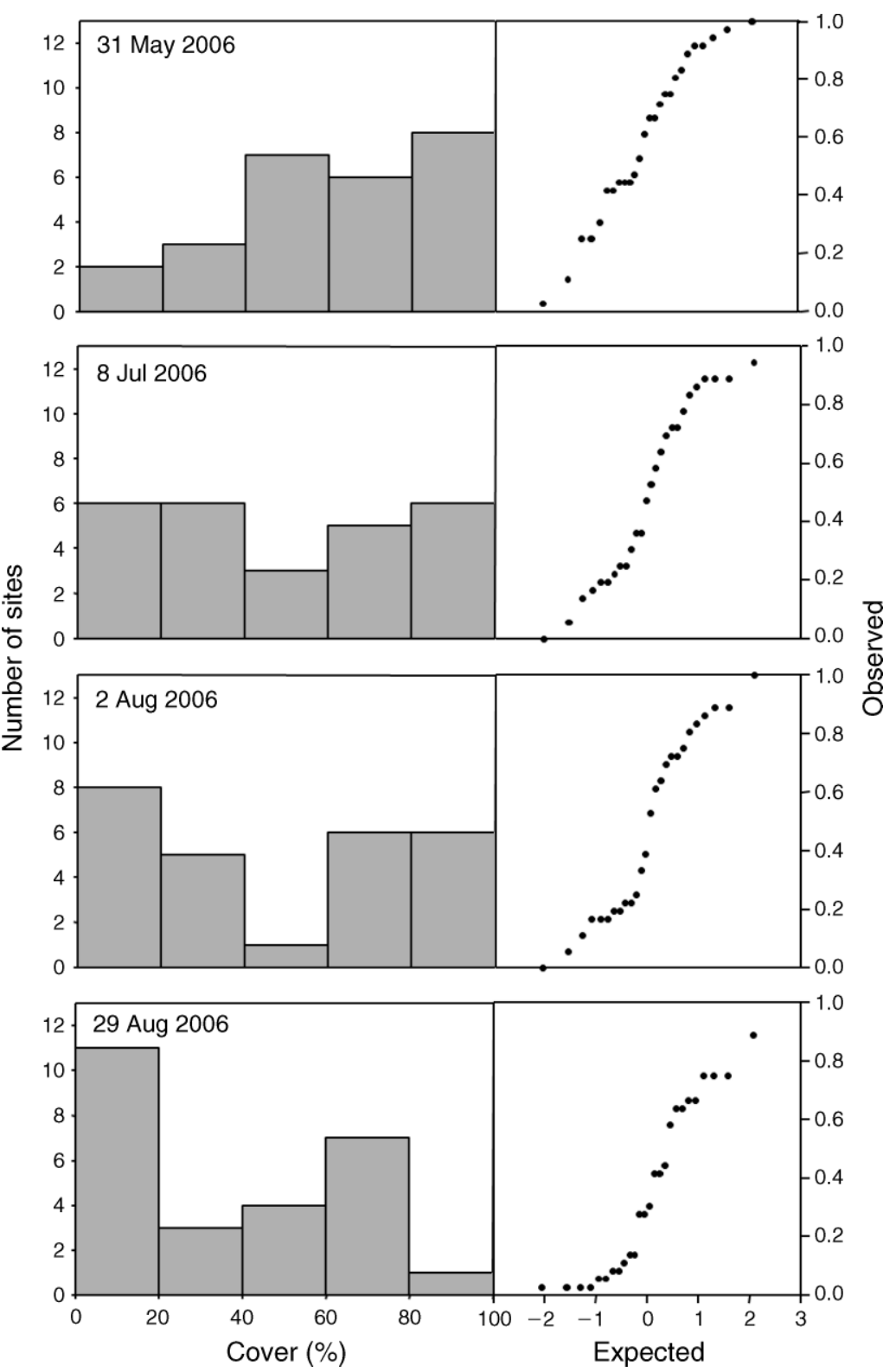

FIG. 6. Changes in distribution of vegetation cover in response to monsoon floods of 2006 shown as histograms (left) and as normal probability (observed vs. expected) plots (right). For normal probability plots, the $x$-axis is the theoretical value of the $i$ th observation from a standardized normal distribution ( $Z$ score), and the $y$-axis is the observed value of the same observation (shown as a cumulative proportion). Prior to the first monsoon flood (31 May), distribution of vegetation cover was approximately normal, but subsequent floods resulted in an increasingly bimodal distribution, as seen by the divergence of modes in the histograms and the characteristic sigmoid shape of the normal probability plots. Results of statistical analysis of these distributions are shown in Table 2.

ity, could similarly perturb desert streams across stablestate thresholds.

While the existence of multiple states in desert streams is driven by the biotic stabilization of channel sediments, the probability of wetland development and persistence (i.e., resilience) in a given stream reach is likely to be heavily influenced by local geomorphic structure via effects on vegetation growth rate and productivity and via effects on flood scour and resulting mortality. In desert streams, constrained canyons support greater duration of surface flow than sections flowing through wide alluvial valleys (Stanley et al. 1997), which in turn influences production, particularly during dry years (Fig. 3b). Further, deposition of fine sediments under ciénega vegetation provides the additional potential feedback mechanism of increased water availability as fine sediments accumulate over the course of ciénega development (Heffernan 2007). In addition, geomorphic 
TABLE 2. Result of statistical analysis of changes in distribution of vegetation cover in response to floods of 2006 monsoon season.

\begin{tabular}{|c|c|c|c|c|c|c|c|c|c|}
\hline \multirow[b]{2}{*}{ Date } & \multicolumn{2}{|c|}{ Lilliefors'† } & \multicolumn{5}{|c|}{ Best-fit parameters } & \multicolumn{2}{|c|}{$\mathrm{BIC} \S$} \\
\hline & Max. diff. & $P$ & $x_{1}$ & $s_{1}^{2}$ & $x_{2}$ & $s_{2}^{2}$ & $q$ & Single normal & Normal mixture \\
\hline 31 May & 0.098 & 0.79 & 0.598 & 0.074 & NA & NA & NA & -12.6 & -16.0 \\
\hline 8 July & 0.140 & 0.21 & 0.231 & 0.167 & 0.765 & 0.167 & 0.501 & -17.1 & -13.5 \\
\hline 2 August & 0.188 & 0.02 & 0.193 & 0.127 & 0.771 & 0.127 & 0.504 & -19.4 & -8.5 \\
\hline 29 August & 0.196 & 0.01 & 0.069 & 0.016 & 0.552 & 0.040 & 0.406 & -14.9 & -4.7 \\
\hline
\end{tabular}

Note: $\mathrm{NA}=$ not applicable.

$\dagger$ Lilliefors' test evaluates the hypothesis that data are normally distributed. Max. diff. = maximum difference.

\$ Best-fit parameters for the superior-fitting distribution are shown; $x_{1}$ and $x_{2}$ are the respective means of the two distributions in the mixture model, $s_{1}^{2}$ and $s_{2}^{2}$ are the respective variances of those distributions, and $q$ is the parameter that determines the weighting of the first distribution (with the second distribution having a weight of $1-q$ ).

$\S$ Greater BIC (Bayes' information criterion) indicates superior fit of either a single normal distribution or a mixture of two normal distributions as described by Eq. 5 .

characteristics such as channel geometry and slope will influence the shear stress associated with a given discharge, while particle-size distribution and arrangement will influence the resistance of sediments to scour. The distribution of these geomorphic characteristics within the drainage network will determine the probability of wetland formation and persistence, and likely exerts strong influence on the spatial distribution of ciénega development within Sycamore Creek (Arizona, USA) and other desert streams.

Relict ciénegas support several endangered fish and plant species (Collins et al. 1981, Meffe et al. 1982, Sheviak 1990), and widespread restoration of ciénegas, which accumulate sediments and are frequently anoxic, could reduce export of sediments and dissolved nutrients to downstream reservoirs. The identification of ciénegas as an alternative stable state in desert streams has important implications for efforts to restore these habitats. While the reestablishment of wetlands in some sections of Sycamore Creek following the elimination of cattle grazing did occur without active restoration, the alternative-state model suggests that such spontaneous recovery may be limited to small areas where local geomorphic structure is particularly favorable to wetland development. Large-scale recovery will likely require concerted efforts to push desert streams into the ciénega state. As for arid terrestrial systems (Holmgren and Scheffer 2001), specific climatic windows may maximize the likelihood of sustained success of restoration efforts. In the Sonoran Desert, periods of sustained baseflow following wet winters, when water availability is high and the likelihood of flood disturbance low, may provide an ideal opportunity for manipulation of vegetation. High productivity during such periods might be sufficient to allow vegetation to withstand the subsequent monsoon floods.

This study represents the first empirically supported example of alternative stable states in a stream ecosystem. Dent et al. (2002) proposed a variety of potential alternative states in stream ecosystems, including a qualitative description of the dynamics described by the model, but did not empirically evaluate those hypotheses. Several recent studies have documented long-term changes in stream ecosystems that persist after the cessation of disturbances, such as stream acidification (Bradley and Ormerod 2002), phosphorus enrichment (Slavik et al. 2004), and agriculturally driven sedimentation (Harding et al. 1998); however, in the absence of any known feedback mechanisms that would generate alternative states, these responses likely represent slower-changing legacies of those disturbances.

The existence and nature of alternative stable states in desert streams is consistent with several recent hypotheses concerning general features of ecosystems subject to regime shifts, including that of Didham et al. (2005), who propose that alternative states arise primarily in systems with strong abiotic-disturbance regimes. The existence of multiple stable states in desert streams, which are subject to severe flashiness and intermittency (Poff and Ward 1989), is generally consistent with this hypothesis; however, in the model presented here an upper limit exists to the severity of disturbance regime that permits alternative states. Furthermore, while the existence of alternative states in desert streams does not appear to require the trait dispersion mechanism proposed by Didham et al. (2005), variation in herbaceous community composition, and therefore in biogeomorphic characteristics, could influence trajectories of systems near thresholds separating alternative basins of attraction.

Dent et al. (2002) suggest the related hypothesis that alternative states in disturbance-driven ecosystems are likely to occur via abiotic mechanisms. In comparison with regime shifts in lakes, alternative states in desert streams do have a strong hydrogeomorphic (i.e., physical) basis, but the fundamental mechanism of feedback in ciénegas (i.e., channel stabilization by vegetation) is biotic in nature. Whether this feedback results in the existence of alternative states depends on the strength of this effect relative to the physical stability of the system. The more general hypothesis that the potential for alternative states and regime shifts in ecosystems is determined by the relative strength of biotic and abiotic forces or processes, rather than the absolute magnitude or other characteristics of one or the other, seems worthy of further investigation. 
Stallins (2006) suggests that biogeomorphic systems in general have the potential to exhibit alternative stable states. Besides ciénegas, multiple-state systems driven by direct feedbacks between vegetation and sediment transport and structure have been identified in tidal mudflats (van de Koppel et al. 2001), coastal sand dunes (Adema and Grootjans 2003, Stallins 2005), rock outcrops in boreal forests (Asselin et al. 2006), the Florida Everglades (Ogden 2005), European salt marshes (van de Koppel et al. 2005), and arid terrestrial systems (Rietkerk et al. 2002, van de Koppel and Rietkerk 2004). In other cases, stabilization of substrate acts as an indirect feedback on other drivers of regime shifts, as in lake eutrophication, where decreased macrophyte cover contributes to sediment re-suspension and internal phosphorus loading (e.g., Sondergaard et al. 1992, Horppila and Nurminen 2001). These biogeomorphic alternative states occur across a wide range of organism life histories, spatial scales, and geophysical contexts. Efforts to identify previously unrecognized or unrealized ecosystem regime shifts should consider the frequency of biogeomorphic feedbacks as generators of multiple states in ecosystems.

\section{ACKNOWLEDGMENTS}

I owe particular thanks to Sam Norlin for his help with vegetation surveys. Marty Anderies provided considerable assistance with model development and analysis. Ryan Sponseller, Stuart Fisher, Ann Kinzig, Julie Stromberg, Jim Elser, and Marty Anderies provided helpful comments that significantly improved this manuscript. Comments from two anonymous reviewers were particularly helpful in clarifying the arguments in this paper. This research was supported by a Graduate Research Fellowship from NSF and a Dissertation Fellowship from the Graduate Division of Arizona State University to J. B. Heffernan.

\section{Literature Cited}

Adema, E. B., and A. P. Grootjans. 2003. Possible positivefeedback mechanisms: plants change abiotic soil parameters in wet calcareous dune slacks. Plant Ecology 167:141-149.

Asselin, H., A. Belleau, and Y. Bergeron. 2006. Factors responsible for the co-occurrence of forested and unforested rock outcrops in the boreal forest. Landscape Ecology 21: 271-280.

Bradley, D. C., and S. J. Ormerod. 2002. Long-term effects of catchment liming on invertebrates in upland streams. Freshwater Biology 47:161-171.

Carpenter, S. 2003. Regime shifts in lake ecosystems: pattern and variation. Ecology Institute, Oldendorf/Luhe, Germany.

Collins, J. P., C. Young, J. Howell, and W. L. Minckley. 1981. Impact of flooding in a Sonoran Desert stream, including elimination of an endangered fish population (Poeciliopsis occidentalis, Poeciliidae). Southwestern Naturalist 26:415423.

Dent, C. L., G. S. Cumming, and S. R. Carpenter. 2002. Multiple states in river and lake ecosystems. Philosophical Transactions of the Royal Society of London B 357:635-645.

Didham, R. K., C. H. Watts, and D. A. Norton. 2005. Are systems with strong underlying abiotic regimes more likely to exhibit alternative stable states? Oikos 110:409-416.

Dudley, T. L., and N. B. Grimm. 1994. Modification of macrophyte resistance to disturbance by an exotic grass, and implications for desert stream succession. Internationale
Vereinigung für theoretische und angewandte Limnologie, Verhandlungen 25:1456-1460.

Fisher, S. G., L. J. Gray, N. B. Grimm, and D. E. Busch. 1982. Temporal succession in a desert stream ecosystem following flash flooding. Ecological Monographs 52:93-110.

Fisher, S. G., N. B. Grimm, E. Marti, R. M. Holmes, and J. J. B. Jones, Jr. 1998. Material spiralling in stream corridors: a telescoping ecosystem model. Ecosystems 1:1934.

Fraley, C., and A. E. Raftery. 1999. MCLUST: Software for model-based cluster analysis. Journal of Classification 16: 297-306.

Graf, W. L. 1988. Fluvial processes in dryland rivers. SpringerVerlag, Berlin, Germany.

Grimm, N. B. 1987. Nitrogen dynamics during succession in a desert stream. Ecology 68:1157-1170.

Grimm, N. B., and S. G. Fisher. 1989. Stability of periphyton and macroinvertebrates to disturbance by flash floods in a desert stream. Journal of the North American Benthological Society 8:293-307.

Groffman, P., et al. 2006. Ecological thresholds: the key to successful environmental management or an important concept with no practical application? Ecosystems 9:1-13.

Harding, J. S., E. F. Benfield, P. V. Bolstad, G. S. Helfman, and E. B. D. Jones. 1998. Stream biodiversity: the ghost of land use past. Proceedings of the National Academy of Sciences (USA) 95:14843-14847.

Heffernan, J. B. 2007. Wetlands as an alternative state in desert streams. Dissertation. Arizona State University, Tempe, Arizona, USA.

Hendrickson, D. A., and W. L. Minckley. 1984. Ciénegasvanishing climax community of the American Southwest. Desert Plants 6(3).

Holling, C. S. 1973. Resilience and stability of ecological systems. Annual Review of Ecology and Systematics 4:1-23.

Holmgren, M., and M. Scheffer. 2001. El Nino as a window of opportunity for the restoration of degraded arid ecosystems. Ecosystems 4:151-159.

Horppila, J., and L. Nurminen. 2001. The effect of an emergent macrophyte (Typha angustifolia) on sediment resuspension in a shallow north temperate lake. Freshwater Biology 46:14471455.

Martin, P. S. 1963. The last 10,000 years. University of Arizona Press, Tucson, Arizona, USA.

May, R. M. 1977. Thresholds and breakpoints in ecosystems with a multiplicity of stable states. Nature 269:471-477.

Meffe, G. K., D. A. Hendrickson, and J. N. Rinne. 1982. Description of a new topminnow population in Arizona, with observations on topminnow-mosquitofish co-occurrence. Southwestern Naturalist 27:226-228.

Ogden, J. C. 2005. Everglades ridge and slough conceptual ecological model. Wetlands 25:810-820.

Poff, N. L., and J. V. Ward. 1989. Implications of streamflow variability and predictability for lotic community structure: a regional analysis of streamflow patterns. Canadian Journal of Fisheries and Aquatic Sciences 46:1805-1818.

Rietkerk, M., M. C. Boerlijst, F. van Langevelde, R. HilleRisLambers, J. van de Koppel, L. Kumar, H. H. T. Prins, and A. M. de Roos. 2002. Self-organization of vegetation in arid ecosystems. American Naturalist 160:524-530.

Scheffer, M., and S. R. Carpenter. 2003. Catastrophic regime shifts in ecosystems: linking theory to observation. Trends in Ecology and Evolution 18:648-656.

Scheffer, M., S. R. Carpenter, J. A. Foley, C. Folke, and B. Walker. 2001. Catastrophic shifts in ecosystems. Nature 413: 591-596.

Schmidt, K. M., J. J. Roering, J. D. Stock, W. E. Dietrich, D. R. Montgomery, and T. Schaub. 2001. The variability of root cohesion as an influence on shallow landslide susceptibility in the Oregon Coast Range. Canadian Geotechnical Journal 38:995-1024. 
Schroder, A., L. Persson, and A. M. De Roos. 2005. Direct experimental evidence for alternative stable states: a review. Oikos 110:3-19.

Sheviak, C. J. 1990. A new Spiranthes (Orchidaceae) from the ciénegas of southernmost Arizona. Rhodora 92:213-231.

Slavik, K., B. J. Peterson, L. A. Deegan, W. B. Bowden, A. E. Hershey, and J. E. Hobbie. 2004. Long-term responses of the Kuparuk River ecosystem to phosphorus fertilization. Ecology 85:939-954.

Smith, D. G. 1976. Effects of vegetation on lateral migration of an anastomosed glacial meltwater river. Geological Society of America Bulletin 87:857-860.

Sondergaard, M., P. Kristensen, and E. Jeppesen. 1992. Phosphorus release from resuspended sediment in the shallow and wind-exposed Lake Arreso, Denmark. Hydrobiologia 228:91-99.

SPSS. 2000. SYSTAT, version 10.0. SPSS, Chicago, Illinois, USA.

Stallins, J. A. 2005. Stability domains in barrier island dune systems. Ecological Complexity 2:410-430.

Stallins, J. A. 2006. Geomorphology and ecology: unifying themes for complex systems in biogeomorphology. Geomorphology 77:207-216.
Stanley, E. H., S. G. Fisher, and N. B. Grimm. 1997. Ecosystem expansion and contraction in streams. BioScience 47:427435.

Suding, K. N., K. L. Gross, and G. R. Houseman. 2004. Alternative states and positive feedbacks in restoration ecology. Trends in Ecology and Evolution 19:46-53.

van de Koppel, J., P. M. J. Herman, P. Thoolen, and C. H. R. Heip. 2001. Do alternate stable states occur in natural ecosystems? Evidence from a tidal flat. Ecology 82:34493461 .

van de Koppel, J., and M. Rietkerk. 2004. Spatial interactions and resilience in arid ecosystems. American Naturalist 163: $113-121$

van de Koppel, J., D. van der Wal, J. P. Bakker, and P. M. J. Herman. 2005. Self-organization and vegetation collapse in salt-marsh ecosystems. American Naturalist 165:E1-E12.

Vaneerdt, M. M. 1985. The influence of vegetation on erosion and accretion in salt marshes of the Oosterschelde, The Netherlands. Vegetatio 62:367-373.

Welter, J. R., S. G. Fisher, and N. B. Grimm. 2005. Nitrogen transport and retention in an arid land watershed: Influence of storm characteristics on terrestrial-aquatic linkages. Biogeochemistry 76:421-440.

\section{APPENDIX A}

Three figures with pictures of gravel bed and ciénega study sites (Ecological Archives E089-076-A1).

\section{APPENDIX B}

Formal analysis of the vegetation flood-response model (Ecological Archives E089-076-A2).

\section{APPENDIX C}

A table listing hydrologic and geomorphic characteristics of study sites (Ecological Archives E089-076-A3).

\section{APPENDIX D}

Collection methods and analysis of height-biomass relationships used to estimate biomass (Ecological Archives E089-076-A4).

\section{APPENDIX E}

Changes in the frequency distribution of vegetation cover from 26 sites along Sycamore Creek in response to winter and monsoon floods of 2005 (Ecological Archives E089-076-A5). 